\title{
Developing Farm-Level Social Indicators for Agri-Environment Schemes: A Focus on the Agents of Change
}

\author{
Jane Mills ${ }^{1, * \mathbb{D}}$, Hannah Chiswell ${ }^{1}$, Peter Gaskell ${ }^{1}$, Paul Courtney ${ }^{1}$, Beth Brockett ${ }^{2}$, George Cusworth ${ }^{3}$ (D) \\ and Matt Lobley 4 (D) \\ 1 Countryside and Community Research Institute, University of Gloucestershire, Cheltenham GL50 4AZ, UK; \\ hchiswell1@glos.ac.uk (H.C.); pgaskell@glos.ac.uk (P.G.); pcourtney@glos.ac.uk (P.C.) \\ 2 Natural England, Worcester WR5 2NP, UK; beth.brockett@naturalengland.org.uk \\ 3 Oxford Martin School, University of Oxford, Oxford OX1 3BD, UK; george.cusworth@zoo.ox.ac.uk \\ 4 Centre for Rural Policy Research, University of Exeter, Exeter EX4 4PJ, UK; m.lobley@exeter.ac.uk \\ * Correspondence: jmills@glos.ac.uk
}

check for

updates

Citation: Mills, J.; Chiswell, H.; Gaskell, P.; Courtney, P.; Brockett, B.; Cusworth, G.; Lobley, M. Developing Farm-Level Social Indicators for Agri-Environment Schemes: A Focus on the Agents of Change. Sustainability 2021, 13, 7820. https:// doi.org/10.3390/su13147820

Academic Editors: José

Manuel Mirás-Avalos and Emily

Silva Araujo

Received: 15 June 2021

Accepted: 1 July 2021

Published: 13 July 2021

Publisher's Note: MDPI stays neutral with regard to jurisdictional claims in published maps and institutional affiliations.

Copyright: (c) 2021 by the authors. Licensee MDPI, Basel, Switzerland. This article is an open access article distributed under the terms and conditions of the Creative Commons Attribution (CC BY) license (https:// creativecommons.org/licenses/by/ $4.0 /)$.

\begin{abstract}
Most monitoring and evaluation programmes for agri-environment schemes focus on understanding the environmental outcomes and the cost-effectiveness of these schemes. Evaluation of the social dimensions of agri-environment schemes, particularly the socio-cultural factors that might influence the quality of engagement with the schemes and the social wellbeing impact of scheme engagement, is limited. This is a critical gap in knowledge as there is growing recognition that without more explicit consideration of the farmers involved in land management as agents of change, the required environmental improvements will not be achieved. The aim of this paper was to undertake a systematic literature review to inform the development of a set of social indicators that can be used to measure the level of farmers' engagement with their scheme agreement and the social sustainability outcomes from participation. Following the literature review and a short-listing ranking exercise with two sets of experts, 20 high-level (composite) social indicators and associated sub-level (component) indicators were identified. A series of scale or ranking questions that can be used to capture the indicator data were also developed and tested. This paper presents the first stage in the development of a robust set of social indicators for agri-environment schemes that will also provide a good indicator of long-term environmental outcomes.
\end{abstract}

Keywords: social indicators; agri-environment; social sustainability; farmer behaviour; socio-cultural; health and wellbeing; monitoring and evaluation

\section{Introduction}

Agri-environment schemes (AESs), whereby farmers are paid for voluntarily undertaking specified environmental actions, formalised as an agreement between the farmer and the State, were first introduced in Europe in the 1980s due to concerns about environmental damage from agricultural intensification. There is a requirement for European Union (EU) Member States to monitor and evaluate the impacts of their agri-environment programmes using a Common Monitoring and Evaluation Programme for Common Agricultural Policy (CAP) [1]. However, even though sustainable agricultural production, including its economic, environmental, and social dimensions, is recognised as one of the principal objectives for the EU's CAP, the social dimension is often lacking from the CAP's monitoring and evaluation programmes [2].

A wealth of research has explored the environmental and agricultural impact of AESs across the United Kingdom and Europe [3,4]. Studies have also considered the economic impacts of AESs [5]. However, despite increasing evidence that the quality of AES engagement (between the agreement holder and their agreement) influences the quality of environmental outcomes, there is still a paucity of research exploring the social dimensions of AESs, particularly the socio-cultural factors that might influence the quality 
of engagement with the schemes and the social wellbeing impact of AES engagement. There is increasing recognition that without explicitly considering land managers as agents of change, the required environmental improvements will not be achieved. It is recognised that these social factors are important determinants of behaviour in the context of AESs and in particular long-term behavioural change and commitment to the aims of the schemes [6-8].

Policy-makers widely accept that indicators are needed to foster and monitor change [9], as evidenced by the EC Monitoring and Evaluation framework for the CAP [1] and the U.K. Government indicator framework for their 25-Year Environment Plan [10]. This requirement has led to the development of indicators as part of England's AES monitoring and evaluation programme to assess scheme performance, such as farmland bird indicators [11]. These indicators help us to both understand and improve scheme efficacy. However, there has been a lack of attention to the conceptual and operational development of social indicators compared with environmental and economic indicators, reflecting the focus of the EU's CAP monitoring and evaluation programme. In fact, this has hindered the systematic evaluation of social change, and in the case of AESs, hindered a deeper understanding of why and how environmental change happens on farms, and with it hindered positive environmental change itself.

Therefore, the aim of this paper is to undertake a comprehensive and systematic literature review to inform the development of a set of social indicators that can be used to measure the level of farmers' engagement with their AES agreement and the social sustainability outcomes from participation. Firstly, the paper identifies indicators that measure the quality of AES engagement based on farmers' willingness and ability to engage with a scheme and their level of connectedness with others. Secondly, social indicators that measure and the impacts of AES engagement on the farmers' quality of life and health and wellbeing are identified. This work forms the basis for the development of an operational framework to underpin the systematic empirical application of the indicators within the field of agri-environment schemes and similar policy tools, such as local water catchment initiatives. This work is timely because in 2018 the U.K. Government launched its ambitious 25-Year Environment Plan to "help the natural world regain and retain good health" [12]. The plan emphasises the Government's renewed interest in developing a transparent and comprehensive set of indicators that will show how the environment is changing and if it is improving over time [10].

The next section sets out the academic context and conceptual framework for the development of the social indicators for AES monitoring and evaluation. This is followed by an explanation of the methodology used to identify the social indicators, a description of the social indicator set, and a discussion of the results.

\section{Conceptual Framework}

Indicators are defined in many ways, but the definition used for this paper is "A quantitative or qualitative factor or variable that provides a simple and reliable means to measure achievement, to reflect the changes connected to an intervention, or to help assess the performance of a development actor". In this paper, we use the term 'social' in a broad sense to include both sociological and psychological perspectives, and we define a social indicator as a measure "used to monitor the social system, helping to identify changes and to guide intervention to alter the course of social change". When considering the application of social indicators to agriculture, and more specifically to agri-environment schemes, we can refine this definition further to encompass the psychological and behavioural factors affecting AES engagement and the intentional or unintentional social outcomes of an AES as it relates to the social world of the agreement holders. However, there is clearly a lack of sufficient conceptual development and empirical evidence to develop such indicators. Therefore, our starting point is a thorough review of the literature on factors affecting farmers' quality of engagement with AESs and the social sustainability outcomes of AESs. 
To understand the environmental behaviours of farmers, consideration needs to be given to both internal factors and the external context in which farmers operate. This has led researchers to examine the relationship between the willingness to adopt or engage with environmental activities and their capacity to adopt or engage. In addition, farmer relations with others and their level of connectedness are increasingly considered an important influence on environmental decision-making, through active engagement in advice and support networks [13]. Indeed, understanding the factors that influence farmer environmental decision-making [13-16] forms an essential backdrop to the development of social indicators of interest here.

Three over-arching and inter-related domains are highlighted by this literature and summarised in the first conceptual framework (Figure 1).

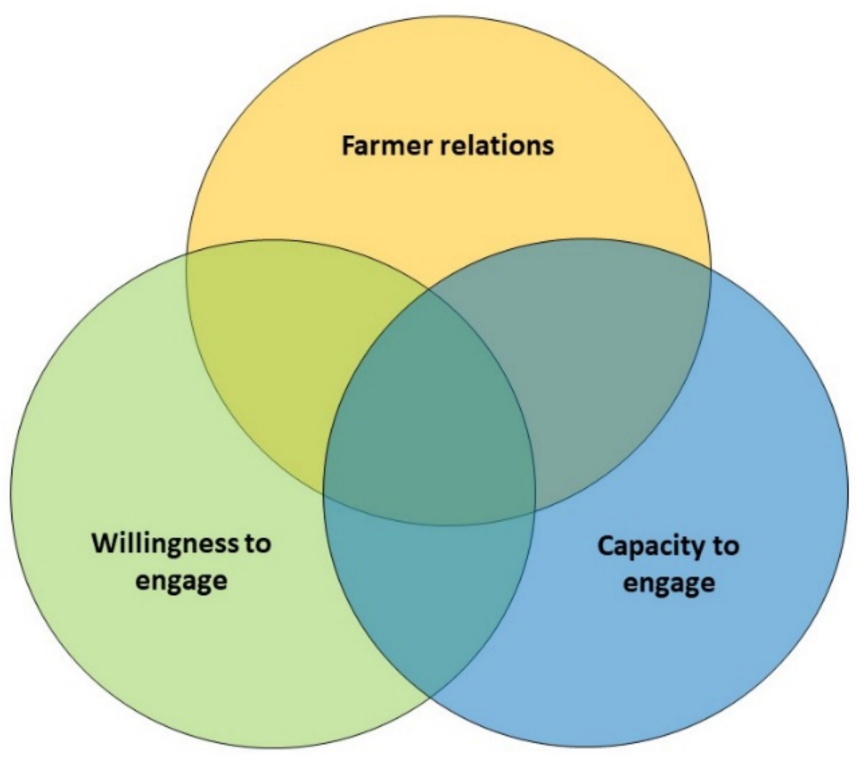

Figure 1. Conceptual framework guiding the literature search on factors affecting AES quality of engagement.

Willingness to engage is focused on the intrinsic factors affecting farmers' environmental behaviours. It reflects the underlying determinants of behaviour, such as the farmers' attitudes, beliefs, values, and norms. For example, commitment to the natural environment and a personal interest in wildlife are clear intrinsic factors identified by a number of studies $[13,17,18]$. Values and norms relating to social status or reputational benefits, or even a sense of moral obligation, have also been shown to influence environmental behaviours $[7,16]$.

In contrast, capacity to engage focuses on the external context in which the farmer operates and how this affects their environmental behaviours. It can relate to farm characteristics and structures, such as farm size, tenure, as well as the economic status, time, and labour, which can facilitate or constrain behavioural changes [15].

Finally, farmer relations are also known to affect environmental behaviours, including the influence of family members, peers, advisers, and government agencies [15,19]. The concept of social capital is useful when thinking about social relations and social networks. For example, increasing social capital through formal and informal farmer-tofarmer interactions can be important for information and advice sharing and normalising environmental behaviours. Studies have also identified the importance of farmer-adviser relationships in influencing environmental behaviours [20].

The second conceptual framework focuses on factors that affect the social sustainability of AESs. These can relate to on-farm conditions or experiences that affect the social world of the agreement holder. Engagement with an AES may have positive or negative social outcomes for the land manager and hence impact the scheme's social sustainability. Social 
sustainability outcomes could, for example, include increased social networks or increased stress due to pressures on time. In the context of this research, our conceptual framework is designed around Bostrom's definition of social sustainability, including quality of life, social justice, social cohesion, cultural diversity, democratic rights, gender issues, human rights, participation, social capital development, and human capability.

These social sustainability outcomes can have a negative or positive effect on environmental outcomes, which in turn can affect engagement factors and quality of engagement. Thus, it is recognised that there may be an overlap between these factors and the potential for mutual reinforcement or feedback loops. Figure 2 provides a simplified visual representation of these concepts and their links to environmental outcomes.

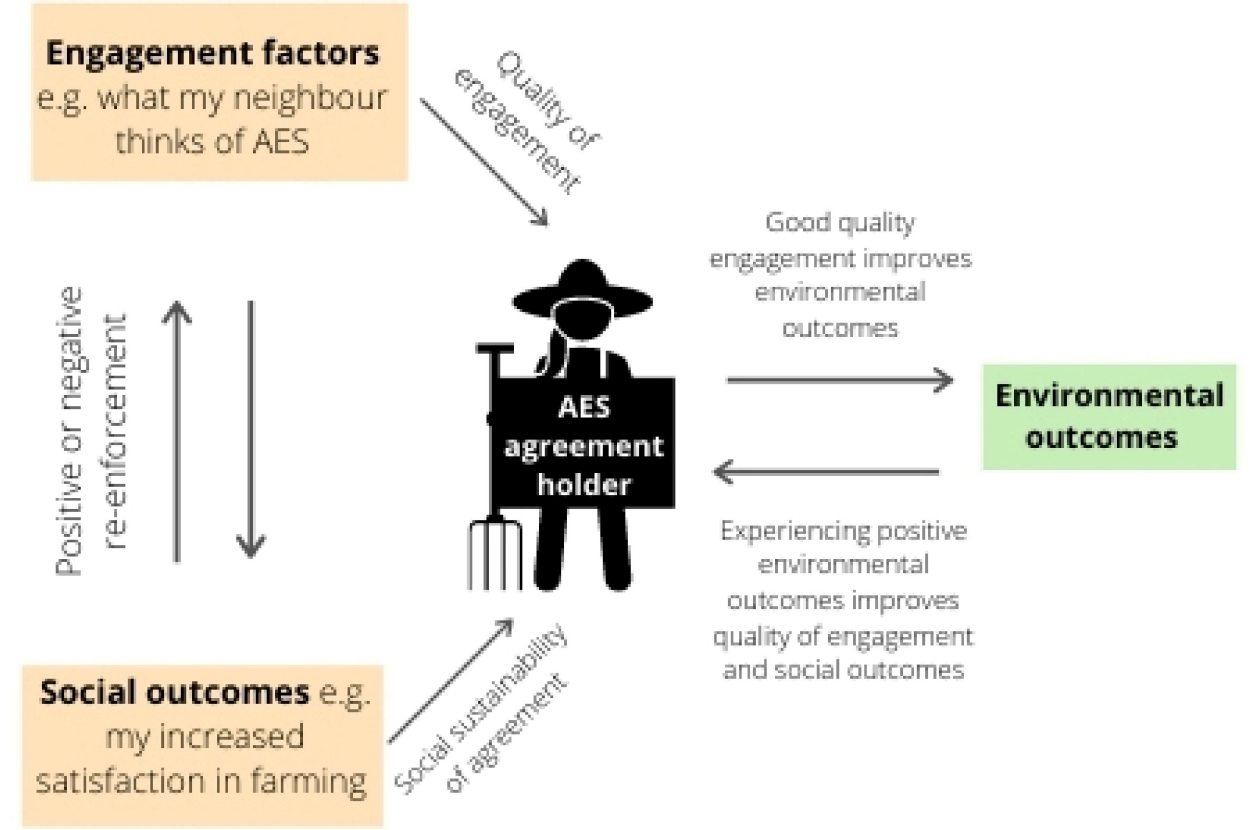

Figure 2. Conceptual framework showing links between AES engagement factors, social sustainability outcomes from AESs, and AES environmental outcomes and feedback loops.

These two high-level conceptual frameworks help to guide a systematic literature review to identify two sets of indicators. The first set aims to measure the nature and 'quality' of farmer engagement with their AES and their link to environmental outcomes. The second set of social indicators measures the social sustainability outcomes that result from a land manager's involvement in an AES.

\section{Method}

To identify the key factors that might influence AES quality of engagement, we used the following three search strings in the literature review to bring each of the three highlevel concepts to life:

- Willingness to Engage Farmer (or land manager, forester) AND "agri environment" (or conservation, biodiversity, agriculture and environment, woodland) AND attitude (or behaviour, awareness, self-identity, mental health, wellbeing, mood disorder, depression, stress, loneliness).

- Capacity to Engage Farmer (or land manager, forester) AND "agri environment" (or conservation, biodiversity, agriculture and environment, woodland) AND knowledge (or training, skills, labour, employment, time, finance, capacity, resilience).

- Farmer Relations Farmer (or land manager, forester) AND "agri environment" (or conservation, biodiversity, agriculture and environment, woodland) AND social capital (or cooperation, groups, collaboration, advice, public, access, antisocial behaviour). 
We undertook a further review of the literature to identify social sustainability indicators in relation to the impact of an AES on the agreement holders' quality of life and health and wellbeing.

We conducted the initial literature search between 29 October 2018 and 5 November 2018, using both the Web of Science and Google Scholar. It is considered good practice to use more than one search engine, as different search platforms are known to yield different results. Although Google Scholar is useful, particularly for identifying grey literature, it is acknowledged that its searches are understood as an 'imperfect tool to perform systematic reviews' with potential for selection bias (see Piasecki et al. [21], p. 809). Due to time constraints for conducting the search and analysis, the search was limited to papers published between 2000 and 2018. The search was open to all geographical regions to capture experiences from other parts of the world. A further search of grey literature (including project reports) was also conducted using Google as a search engine and checking the websites of relevant U.K. Government agencies (Natural England, Forestry Commission and Department for Environment, Food and Rural Affairs).

The search terms yielded 262 articles, which were uploaded to the reference management software, EndNote. In addition, relevant draft or unpublished reports suggested by external experts comprised of government agency staff and academics were also added, resulting in a total of 352 documents.

Each article was screened by a team of four who examined the abstracts and excluded those that were not relevant to the purpose of the study.

We examined the reference lists of five key papers that appeared in all three searches (willingness; capacity; farmer relations) [3,6,22-24] for additional relevant references and added 19 of these to EndNote, all within the search timeframe. This process resulted in 175 documents remaining for full-text analysis. In a final step, after a more thorough reading of the full-text, a further 53 articles were excluded for not meeting the inclusion criteria, leaving 122 documents included in the review. A summary of the process is included in Figure 3.

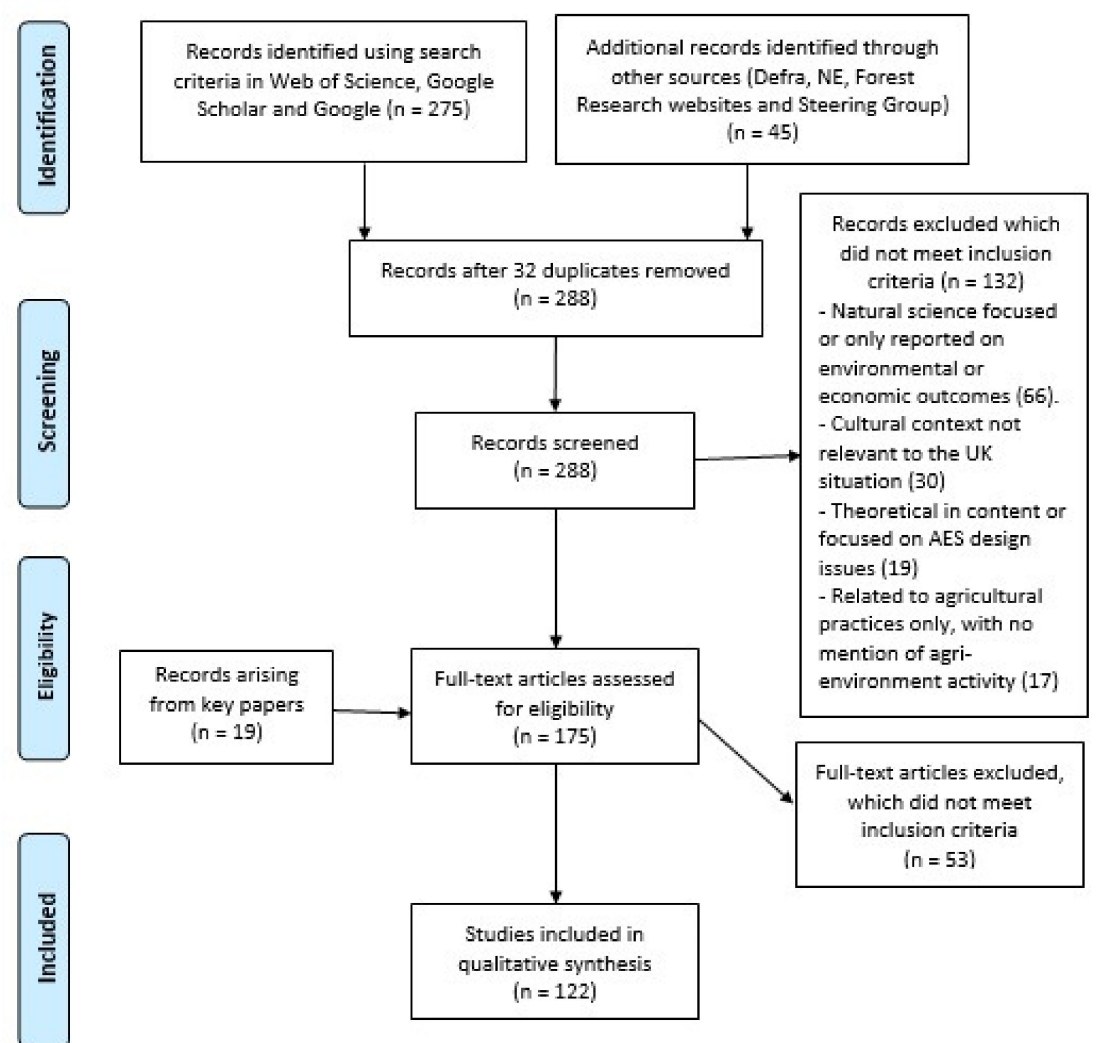

Figure 3. PRISMA flow diagram for the systematic review. 
We undertook the literature analysis using the qualitative data analysis software QSR NVivo 11. The same four team members who undertook the literature search and screening also conducted the analysis. Using a coding framework protocol to aid consistency, salient segments from each document were coded to a succinct node. These nodes were then used to produce indicator variables, which formed the basis of the indicators. Using expert judgement, some variables were combined to produce composites in order to present a more robust indicator. One person checked a $10 \%$ sample of the papers analysed to assess the consistency of the coding and ratings. Very few differences in the analysis were identified, providing confidence in the approach taken.

For each engagement factor or social sustainability outcome identified, a rating for the level of impact and strength of the link between social and environmental outcomes was assigned based on a five-point scale. We also applied a three-point scale rating based on the strength of the evidence, indicated by the study's design, as recommended by the Department for International Development [25]. All ratings were assigned based on the expert judgement of the social scientists familiar with the subject area and added to QSR NVivo as document attributes via the File Classification feature.

We completed a final short-listing of the indicators using a ranking exercise undertaken by two sets of experts: five AES researchers who were also members of a Government Social Science Expert Panel; and six Natural England Farm Conservation Advisers who advise land managers on AES implementation.

Both sets of experts used a five-point scale to rank the indicators on their (i) usefulness/relevance and (ii) the feasibility of implementing the indicators. The literature had also revealed a need to distinguish between high-level indicators-which related to specific forms of change that were essentially multi-dimensional concepts (for example, farmers' interest in the environment) - and sub-level indicators, identified as being components of the multi-dimensional concept, which when taken together provided a single index of change in the high-level indicator (e.g., awareness of species and habitats, interest in landscape assets, extent of environmental knowledge). This need to distinguish between high and sub-level indicators was revealed in two ways. First, in some cases concepts were identified that were clearly a relevant indicator of interest, but presented a number of ways that the item might be measured-in addition to the high-level indicator itself. An example is farmers' interest in (and awareness of) environment, representing a high-level indicator, but which could also be measured by extent of environmental knowledge and sense of environmental responsibility. This implied the need for a number of sub-level indicators to ensure reliability of the indicator and (ultimately) validity of the measurement. Second, the literature identified a conceptually relevant indicator, but was inherently devoid of any direct measurement without assembling plausible sub-level indicators to provide the measurement component(s). A relevant example can be found in the higher-level indicator bonding social capital, which can be measured through sub-indicators, such as extent of group working, extent of knowledge sharing, and level of social trust. In the majority of cases, the high-level indicators are effectively composite indicators, with sub-level indicators being component indicators compiled to produce a single index of change, in turn providing a robust and comprehensive way of monitoring change in the principal—or high-level—concept of interest. In cases where high-level indicators were identified as single item measures (i.e., succession), the respective sub-level indicator simply refers to a more specific measure of the concept (e.g., planning for succession).

To help assess their reliability, we also asked the experts to rank each sub-level indicator based on how relevant they thought these sub-level indicators were for capturing changes in the associated high-level indicator. For each indicator, the mean and mode of the range of scores provided by the experts were calculated. Those indicators that received a low score were recommended for removal from the indicator list. The short-listing process resulted in removing or merging 13 of the high-level indicators and removing 14 sub-indicators. In addition, based on the suggestions provided in the ranking exercises, three additional indicators were proposed. 
In a final step, a series of scale or ranking questions that can be used to capture the indicator data were developed. When devising each question, consideration was given to the following criteria:

- Is this the most direct and robust way of asking the question?

- Is the question really linked to the quality of AES engagement or to social outcomes of an AES?

- Is the question measuring something that will change as a result of AES involvement?

- Is the question taking too much for granted?

- Is the question unambiguous and in plain English?

We tested these questions with 19 AES agreement holders representing different agricultural systems across England and incorporated their feedback into a revised survey form (see Supplementary Materials).

Whilst it is acknowledged that no indictor is perfect for all purposes, through the literature review we have aimed to identify the indicators that address the most important issues related to achieving environmental and social sustainability outcomes and are scientifically valid.

\section{Results}

\subsection{Quality of AES Engagement Indicators—Willingness to Engage Indicators}

We present the key indicators identified as affecting the quality of farmer engagement with an AES related to willingness to engage in Table 1.

Table 1. Indicators and sub-indicators related to the willingness to engage.

\begin{tabular}{|c|c|}
\hline High-Level Indicators & Sub-Indicators \\
\hline $\begin{array}{c}\text { Interest in (and awareness of) } \\
\text { environment }\end{array}$ & $\begin{array}{l}\text { Level of awareness of and interest in wildlife } \\
\text { (species and habitats); } \\
\text { Level of awareness of and interest in cultural and } \\
\text { landscape assets; } \\
\text { Extent of environmental knowledge; } \\
\text { Extent of sense of environmental responsibility; } \\
\text { Extent of unsubsidised environmental activity. }\end{array}$ \\
\hline $\begin{array}{l}\text { Attitudes and beliefs about farming } \\
\text { (self-identity) }\end{array}$ & Attitudes to farming and self-identity. \\
\hline Engagement with advice and training & $\begin{array}{l}\text { Level of engagement with environmental advice; } \\
\text { Level of rapport with advisor; } \\
\text { Level of engagement in training; }\end{array}$ \\
\hline Level of AES experience & $\begin{array}{l}\text { Length of previous AES experience; } \\
\text { Level of confidence in environmental skills/abilities; } \\
\text { Level of understanding of the AES rationale. }\end{array}$ \\
\hline
\end{tabular}

\subsubsection{High-Level Indicator: Interest in (and Awareness of) Environment}

The literature review revealed that personal interest in the environment affects farmers' attitude towards the environment and was the most commonly identified indicator affecting farmers' quality of engagement with agri-environment activities. We identified several different factors in the literature as influencing farmers' interest in and awareness of the environment. Sub-indicators that make up the high-level indicator are:

Interest in Wildlife: Many studies identified that the level of farmers' personal interest in wildlife was positively correlated with a willingness to undertake wildlife-friendly measures [17,26-28]. For example, a study of a scheme for meadow bird protection the Netherlands showed that farmers with an "eye for the birds" improved environmental outcomes by protecting more nests and chicks before carrying out farming activities [28].

Interest in and Awareness of Cultural and Landscape Assets: Farmers' quality of engagement with agri-environment activities is also influenced by their interest in and awareness 
of the wider landscape and cultural assets such as historic buildings, field and farm boundaries, and archaeology. Three distinct mechanisms were identified. First, interest in conserving features is regarded as important in terms of a landscape's social and cultural history. Second, the appreciation of cultural and landscape assets as connected to personalised accounts of place. Third, linking the beauty and character of landscapes and features to particular traditions of the land management that had produced them $[29,30]$.

Extent of Environmental Knowledge: The evidence revealed that an increase in farmers' environmental knowledge heightened their sense of environmental responsibility. For example, studies have shown that a lack of knowledge concerning bird population trends and some misinterpretation of habitat requirements may limit farmers' sense of responsibility and willingness to adopt an AES [17,31,32].

Sense of Environmental Responsibility: Related to the extent of environmental knowledge, several studies have highlighted the importance of a farmer's sense of environmental responsibility in their engagement with an AES. Feeling high levels of environmental responsibility can relate to a strong sense of belonging or place (e.g., Saxby et al. thus promoting continued AES work). Feeling a lack of environmental responsibility can reduce engagement with agri-environmental activities, such as a failure to address water pollution [33].

Unsubsidised environmental activity: An interest in the environment is often reflected in unsubsidised environmental activity on the farm. Morris et al. [34] found that those who had already undertaken enhancements under their own initiative, and those with some distinguishing environmental feature on the farm, such as a river, were more inclined to engage in an AES.

\subsubsection{High-Level Indicator: Attitudes and Beliefs about Farming (Self-Identity)}

Self-identity is the extent to which behaviour is considered to be consistent with the self and can be related to the social group that the farmer identifies with. It reflects the farmer's personal value system and worldview based on their own experiences and moral values and acts as an internal frame of reference, determining their perceptions of external factors and their own preferences. It has been suggested that behaviours closely associated with self-identity are more likely to persist over time, as the more the behaviour is repeated, the more important it becomes to the individual's self-concept [35]. Sub-indicators that make up the high-level indicator are:

Attitudes to Farming and Related Self-Identity: Farming identities are partly composed of perspectives on what it is to be a 'good farmer'; an idealised 'identity' that the farmer strives to imitate that can contribute to decisions on whether to engage in agri-environment activities or not. The perceived loss of self-identity as it relates to productivist ('food producer') farming ideals as a result of engaging with an AES can act as a motivational deterrent to fully engage [36,37]. Differing levels of commitment to environmental responsibility, agricultural productivity, and farm business management have clustered around a three-fold identity typology: (i) the profit maximiser, (ii) the food producer, and (iii) the custodian $[13,38,39]$.

\subsubsection{High-Level Indicator: Engagement with Advice and Training}

The weight of evidence suggests that levels of engagement with advice and training are an important indicator reflecting the quality of engagement with an AES. Sub-indicators that made up this high-level indicator related to the level of engagement with advice or training and the level of rapport with the adviser.

Level of Engagement with Advice: There was evidence that those who have received on-farm advice are more likely to value and engage in environmental activity. For example, Gabel et al. [40], in a study of 133 farmers in Switzerland, found that the group who received on-farm advice for six years were more inclined to believe in the compatibility of biodiversity conservation and production and the importance of biodiversity than those who had not received advice. 
Level of Engagement with Training: There is also evidence that active involvement in a formal environmental training course can affect the quality of environmental engagement and environmental outcomes. Lobley et al. [41], in a study of 48 farmers involved in an AES in England, found that training farmers increased their confidence in their abilities, their attitudes to agri-environmental management, and ultimately the agri-environmental outcomes on the farm.

Level of Rapport with Adviser: The level of rapport that the farmer has with the adviser is also an important factor. If the farmer is willing to communicate with the adviser and engage in an open and constructive dialogue, good environmental outcomes can be achieved. For example, a perceived good working relationship between fen owners and managers and their Natural England adviser in England was correlated with the successful delivery of lowland fen maintenance/restoration [42]. Such positive environmental outcomes are particularly likely where farmers have been able to develop a relationship with a particular adviser over a sustained time period [43].

\subsubsection{High-Level Indicator: Level of AES Experience}

Length of previous AES experience can increase environmental knowledge and skills, response efficacy, and an understanding of the AES rationale. Studies have found that length of experience within an AES can positively affect future AES engagement $[18,19,44,45]$. Experience is believed to increase the level of skill and knowledge of a particular practice, which, in turn, increases the efficacy of the behaviour [46]. Lobley et al. [41] suggested that farmers with more experience of an AES recognise the importance of relevant knowledge and become more receptive to training and advice. Increased AES experience can relate to 'response efficacy' in that farmers following AES practices for a number of years may start to notice the environmental benefits [24]. As Mettepenningen et al. found, the more a farmer is convinced of the effectiveness of the schemes, the higher the probability that he/she will participate in them. Furthermore, through longer-term experience, farmers may develop a greater understanding of the environmental rationale for a practice and undertake it more broadly across the farm, often as unsubsidised activity [24]. Conversely, negative experiences due to AES participation can also influence the quality of engagement. For example, if AES activities lead to increased predation of smaller birds by birds of prey, or increased fox, badger, and rabbit populations, farmers are less likely to engage with an AES [47].

\subsection{Quality of AES Engagement Indicators-Capacity to Engage Indicators}

Table 2 presents the key engagement factors identified in the literature that affect the nature and quality of farmer engagement in an AES linked to capacity to engage.

Table 2. Indicators and sub-indicators related to the capacity to engage.

\begin{tabular}{cl}
\hline High-Level Indicators & \multicolumn{1}{c}{ Sub-Indicators } \\
\hline Succession & Planning for succession \\
\hline Lifecycle & Stage in lifecycle \\
\hline Land manager education & Level of formal education \\
\hline Farm tenure & Tenure status \\
\hline Financial security & Level of financial security \\
\hline
\end{tabular}

\subsubsection{High-Level Indicator: Succession Status}

Evidence of the effects of succession status on environmental behaviour is often contradictory. Some research suggests that farmers without successors are more likely to disengage from full-time agriculture and extensify, thus benefitting the environment [48-50]. However, Riley's study of hay meadows in the Peak District found that the lack of a successor was often a reason for farmers not to enter their land into a conservation agreement 
due to 'winding-down', poor labour availability, or wanting to have the flexibility to sell the land. Others failed to find any evidence to show that succession and business trajectory were determinants of environmental change on farms or the uptake of woodland incentives [51]. While the succession literature does not amount to an overarching consensus regarding environmental behaviour, pockets of evidence indicating a clear relationship between succession status and a positive or negative relationship with AES engagement, coupled with feedback from the Farm Conservation Advisers, resulted in the indicator being retained.

\subsubsection{High-Level Indicator: Lifecyle}

Lifecycle stage may be a better indicator of the quality of engagement in an AES than succession status, although it can be very complex to determine on multi-generational farms. According to Farmer-Bowers and Lane, many of the strategic decisions farming families make depend on their family's stage in life or the 'life-cycle'. Expansion and retrenchment are 'switched on and off' at different times in the farming family lifecycle $[49,50]$. Thus, life-cycle stages can be indicative of different motivations and pathways that have a direct impact on environmental decision-making [52]. These stages might, for example, include periods of major restructuring, farm expansion, and landscape change as the farm is prepared for a successor, which might or might not be compatible with AES engagement. Alternatively, the farmer could be at the stage of approaching retirement and winding down [53] and, hence, more amenable to schemes that involve extensification of the farming system.

\subsubsection{High-Level Indicator: Land Manager Education}

In many studies, farmers' formal education has proven to be one of the strongest variables determining conservation behaviour $[54,55]$. It is generally argued that farmers with a comparatively low formal education (e.g., left school without taking exams) are less likely to participate in agri-environmental schemes or to adopt environmentally friendly farming practices. Wilson and Hart [18] found a positive relationship between farmers level of education and participation in an AES across ten countries in Europe. Those who completed schooling were far more likely to engage in an AES than those who did not complete their schooling.

\subsubsection{High-Level Indicator: Farm Tenure}

Studies have shown that tenant farmers will demonstrate a lower degree of engagement with AESs than landowner managers [44,56]. In most of the ten EU countries Wilson and Hart investigated, tenure played some role in regard to scheme uptake. Those farmers with more than $50 \%$ of their holding as freehold property were more likely to enter into an AES than those owning less than $50 \%$ freehold. Most tenant farmers did not enter schemes for two major reasons: uncertainty about long-term tenancy agreements with the landlords and lack of incentive to join if agri-environmental payments were not shared with the tenants. Similarly, results from a study by Fish et al. found that some tenant land managers were reluctant to engage in an AES because activities did not lead to a corresponding reduction in rent or they did not receive any of the benefits. There was also a reluctance to protect or enhance landscape features they did not own, partly because of the high cost of tenanted land.

\subsubsection{High-Level Indicator: Financial Security}

Although not specifically identified during the literature review, this indicator was added following the short-listing exercise in which the experts felt, based on their experiences, that financially secure farmers were more likely to have the time and resources to more fully engage with their AES than those who were struggling financially. Although this indicator is more economic than social, it was considered an important factor in affecting the quality of AES engagement and therefore added to the list of indicators. There is also 
the potential to develop further economic-focused indicators in the future. However, it was also acknowledged that capturing such sensitive data could be problematic.

\subsection{Quality of AES Engagement Indicators-Farmer Relations with Others Indicators}

The key engagement factors identified in the literature that affect the nature and quality of farmer engagement in an AES, as linked to their connectedness and general level of social engagement, are presented in Table 3.

Table 3. High-level indicators and sub-indicators indicating quality of farmer relations with others.

\begin{tabular}{cl}
\hline High-Level Indicators & \multicolumn{1}{c}{ Sub-Indicators } \\
\hline \multirow{2}{*}{ Bonding social capital } & $\begin{array}{l}\text { Extent of group working; } \\
\text { Extent of information and knowledge sharing; } \\
\text { Level of social trust. }\end{array}$ \\
\hline \multirow{2}{*}{ Bridging social capital } & $\begin{array}{l}\text { Extent of engagement in non-agricultural } \\
\text { networks; } \\
\text { Extent of public acknowledgement. }\end{array}$ \\
\hline \multirow{2}{*}{ Linking social capital } & Ability/desire to form positive relationships \\
& with government agency staff; \\
& Level of social trust with government. \\
\hline \multirow{2}{*}{ Cultural (symbolic) capital } & Extent of respect amongst peers; \\
& Extent of advising other land managers. \\
\hline
\end{tabular}

\subsubsection{High-Level Indicator: Bonding Social Capital}

Evidence from the literature suggests that bonding social capital, characterised by strong ties within groups or families (homogeneous individuals) that are high in reassurance and support, is an important indicator reflecting the quality of engagement with an AES. Sub-indicators that made up this high-level indicator related to the extent of group working and information and knowledge sharing and levels of social trust.

Extent of Group Working: Several studies have shown that the presence of bonding social capital within a group of farmers can result in positive environmental outcomes. Mills et al., in a study of a farmer's group in Wales, found that enhanced environmental outcomes were achieved by collective commitment-making and a sense of collective efficacy. Similarly, Wynne-Jones [57], looking at the same group, found that group membership gave them the support and encouragement needed to undertake work that they would not have done otherwise.

Extent of Information and Knowledge Sharing (Farmers' Group): There is also evidence that increased networking and the building of close relationships among farmers are more likely to lead to information sharing and knowledge exchange, as well as collaborative work [58]. Barnes et al. [33] and Mills et al. [59] found that information sharing within a group and making individual farmer practices visible to their peers can change perceptions of what is deemed as acceptable farming practices (e.g., pro-environmental behaviours).

Level of Social Trust: Bonding social capital is characterised by strong social trust. This social trust enables the information and knowledge sharing outlined above. However, if this trust is absent, there is a danger that group working can have negative effects on environmental achievements. Emery and Franks [60] identified fear of exposure to the judgement of others as a potential barrier to involvement in collective AES agreements. Additionally, there may be a potential lack of effective AES engagement if the scheme's objectives do not fit with the cultural norms of their peer group, a situation that is unlikely to occur in the presence of strong social trust.

\subsubsection{High-Level Indicator: Bridging Social Capital}

Bridging social capital refers to social connections between individuals who are dissimilar with respect to socio-economic and other characteristics (heterogeneous individuals). 
However, such connections contribute an advantage through bringing new information and perspectives and introductions to new networks [61]. The extent of bridging social capital appears to have an overall positive effect on AES engagement. Sub-indicators that make up the high-level indicator:

Extent of Non-Agricultural Networks: Research has shown the benefits that new networks, linkages, and flows of information can have for changing social and farm business activity [62]. Those who are frequently engaged in non-agricultural networks are also thought to be more likely to be involved in AESs as these farmers feel a greater social responsibility [63]. The mechanism for contact with the general public is mainly through educational links and interaction with people interested in conservation and particularly walkers on the farm [64].

Extent of Public Acknowledgement: AES engagement can build up more cooperative and appreciative bridging social ties with the non-farming community [65]. According to Kuhfuss et al., farmers who experience acknowledgment for their contribution to protecting the environment are more likely to maintain the adopted practices even in the absence of payment. They may value external positive judgements and might fear social disapproval if they return to their less environmentally friendly practices.

\subsubsection{High-Level Indicator: Linking Social Capital}

Linking social capital is a term used to describe networks of people characterised by power differences, such as links between farmers and institutions (e.g., government agencies). Such connections are important for accessing support from institutions through personal contacts. Sub-indicators that make up the high-level indicator:

Ability/Desire to Form Positive Relationships with Government Agency Staff: Hall and Pretty [66], in a study of Norfolk farmers, revealed differences in farmers' ability and desire to form positive working relationships with government agency staff, which affected the level of support they achieved and hence environmental outcomes. Farmers with sustainable farms had success-based identities and stronger feelings of self-efficacy about their interaction with government agency staff and welcomed the prospect of farm visits from advisers and regulators. Conversely, farmers who fundamentally disagreed with the direction of agricultural policy and were aware of polluting and illegal practices on their farms were wary of contact with government agency staff.

Level of Social Trust with Government: Polman and Slangen [63] found that farmers who do not trust the government are less likely to conclude AES contracts. The feeling that government departments lacked the understanding and operational knowledge of farmlevel practices often compounded this outcome [62]. In a situation where an AES was codesigned with farmers and government agencies, an agreement on adapted management of ditches and shores to improve water quality and biodiversity was achieved where previously there had been low levels of trust [67].

\subsubsection{High-Level Indicator: Cultural (Symbolic) Capital}

Cultural capital is a form of symbolic capital that refers to the accumulation of knowledge, behaviours, and skills that demonstrate a farmer's competence, which in turn impacts his/her social status or standing in society. Sub-indicators that make up the high-level indicator:

Respect Amongst Peers: Evidence of respect and positive judgements by other farmers for their AES activities demonstrates prestige (symbolic capital) and reinforces AES engagement. However, loss of prestige or respect amongst peers resulting from AES participation can reduce the quality of AES engagement [68]. Burton et al. [6] found that farmers were demotivated to participate in an AES because of a perceived inability to earn the desired levels of cultural capital through the land management options prescribed compared with productivist techniques they would otherwise pursue. However, more recently, it has emerged that AES engagement and good environmental behaviour is increasingly capable of reproducing cultural capital [69]. 
Advising Other Farmers: Burton and Paragahawewa [7] suggest that evidence of farmers advising other farmers on the implementation of their scheme demonstrates cultural capital. This interaction reinforces the idea that these practices are socially accepted by their peers, which means that they are more likely to become the focus of farm objectives. Saxby et al. [70] found that farmers involved in the North Yorkshire Cornfield Flowers Project had developed specialist plant skills and their advice was respected both within the project by other farmers and by agencies. However, these farmers also recognised that their counterparts outside of the project might not appreciate their conservation work.

\subsection{Social Sustainability Outcome Indicators}

As no studies explicitly considered the social sustainability of AESs, the review focused on suitable indicators from studies on the social sustainability of agriculture [71-73]. Even with these broader studies, few have measured social sustainability, partly due to its subjective character and the limited availability of required data. Studies that have looked at the social sustainability of farming have included issues such as measures of the quality of life on farms, including health and safety indicators, measures of the likelihood of farm succession, sectoral resilience and demographic change (ageing, migration, mobility), measures of educational participation and employment creation, risk of isolation, and access to services.

Farming is widely recognised as a stressful occupation that can impact mental and physical health [74]. Farmers face numerous stressors, including long working hours, time constraints, unpredictable weather, uncertain markets, untimely equipment breakdowns, social and geographical isolation, and increasing regulation, among other things [75-77]. Given what is known about the impact of farming on mental health, it is surprising that only two studies were identified that looked at the interlinkages between mental health and wellbeing and AES participation [70,78]. Due to this paucity in AES-specific research, we also drew on studies that have looked at the quality of life and mental health and wellbeing effects of agriculture more generally to make inferences about the impact of AES participation on mental health.

The social indicators identified of relevance to the impact of AES participation on the farm business and land manager's quality of life and health and wellbeing are presented in Table 4.

Table 4. High-level indicators and sub-indicators indicating social sustainability outcomes of AES participation.

\begin{tabular}{|c|c|}
\hline High-Level Indicators & Sub-Indicators \\
\hline \multicolumn{2}{|c|}{ Social sustainability outcomes-Resilience } \\
\hline Farm business resilience & Response to shocks \\
\hline \multicolumn{2}{|c|}{ Social sustainability outcomes-Quality of life } \\
\hline Employment and working conditions & $\begin{array}{c}\text { Holidays taken } \\
\text { Average Peak working hours }\end{array}$ \\
\hline Job satisfaction & $\begin{array}{c}\text { Work-life balance } \\
\text { Being a farmer } \\
\text { Freedom of decisions }\end{array}$ \\
\hline Quality of life & Satisfaction with quality of life \\
\hline \multicolumn{2}{|c|}{ Social sustainability outcomes-Health and wellbeing } \\
\hline Happiness & $\begin{array}{l}\text { Happiness } \\
\text { Worthwhile }\end{array}$ \\
\hline Physical and mental health & $\begin{array}{l}\text { Physical health } \\
\text { Mental health }\end{array}$ \\
\hline
\end{tabular}


Table 4. Cont.

\begin{tabular}{cc}
\hline High-Level Indicators & Sub-Indicators \\
\hline & Workload \\
Stress levels due to AES & Administration and bureaucracy \\
& Inspections \\
& Financial issues \\
& Environmental enjoyment \\
\hline
\end{tabular}

\subsubsection{High-Level Indicator: Resilience}

Resilience refers to the ability of farm businesses to recover quickly following difficulties and can affect the quality of AES engagement. For example, it might relate to the farm business's level of financial security, which can affect a farm's ability to bounce back following a shock. Some evidence suggests that AES payments can help improve a business's financial security. For example, Mills [64] found that scheme payments in England helped stabilise incomes and offered the security of a regular income twice a year. The payments also made it easier to budget for lean months and the 10-year time horizon of the AES helped with financial planning. Similarly, Ingram et al. [52] found that payments for an AES in Wales offered financial security and were viewed as a way of keeping the farm business going when farm incomes were low. There is also evidence that AES funding can facilitate business restructuring and long-term adjustment to increase farm business resilience, particularly in a shift from productivism to cost-efficiency $[52,79]$.

\subsubsection{High-Level Indictor: Quality of Life-Employment and Working Conditions}

The literature on social sustainability in agriculture revealed indicators that can serve to measure the impact of AES participation on employment and working, in terms of the extent to which an AES affected the number of holidays taken, or average peak working hours $[71,80,81]$. For some land managers, an AES can be an opportunity to extensify their farming system and reduce workloads; for others, it can add to existing workloads. For example, Mills [64] found that around 27\% of agreement holders for an AES in England reported an increased workload as a result of the scheme. Reasons stated for this increased workload included an intensification of boundary work, such as hedges and walling, and more scrub management. Conversely, reasons given for decreases in workload included less hedge cutting, reduced grassland inputs, and stock numbers.

\subsubsection{High-Level Indictor: Quality of Life-Job Satisfaction}

Job satisfaction is known to influence quality of life [82]. The FLINT study [71] identified a number of variables that can affect job satisfaction for agricultural workers. We suggest that three of these can be used to identify whether an AES has contributed negatively or positively to job satisfaction: work-life balance, being a farmer, and freedom of decision-making.

Work-life balance: In the context of AESs, satisfaction with work-life balance relates to the extent to which AES engagement allows the farmer to do things that she or he likes doing in comparison to job duties.

Being a farmer: Satisfaction with being a farmer relates to the extent to which AES engagement affects the perception of the profession chosen and its associated lifestyle.

Freedom of decisions: Freedom of decisions refers to farmers' capacity to make their own decision about joining/rejoining an AES and how they manage their land once in an AES. One outcome from AESs where management practices are heavily prescribed with limited flexibility is a sense that prescriptions are imposed in a top-down way with little consideration given to local or tacit knowledge. A sense of lost control over their land management can prevail, resulting in feelings of dispossession, affecting their engagement with an AES and, therefore, environmental outcomes [36]. In contrast, with AESs that give farmers the control over delivering the management required, such as results-orientated AESs, a much greater sense of agency is evident, which is likely to lead to improved 
environmental outcomes. For example, Wezel et al. [83], in a survey of 79 mountain farmers in 5 countries in Europe, found that almost two-thirds of farmers thought that a result-oriented approach to AES would promote more direct and efficient management of biodiversity on their farm.

\subsubsection{High-Level Indicator: Quality of Life}

Quality of life is commonly assessed through self-reported life satisfaction and is usually dealt with alongside other aspects of subjective and personal wellbeing, themselves self-reported measures and described further below. Heo et al.'s study [84] of U.S. farmers serves to highlight the potential to further explore the life satisfaction of farmers and the importance of stress, risk, and control to the quality of life experienced by them. However, Heo et al.'s focus on finance-related psychological factors has limited relevance to the specific case of AESs.

\subsubsection{High-Level Indicator: Health and Wellbeing-Happiness (Subjective Wellbeing)}

There is considerable interest among governments in the measurement of subjective wellbeing. The World Happiness Report [85] compiles data from 150 countries and has revealed correlations between happiness and a strong social environment, a connection to the natural environment, and differences between rural and urban dwellers. In the United Kingdom, the annual personal and economic wellbeing report compiles data to monitor the wellbeing of the wider population but with less emphasis on causality. Other work (See for example, [86-88]) has broadly shown happiness to be a product of the success achieved in earning a living, raising a family, being in good health, and working in an interesting and secure job.

These concepts are equally pertinent at the farm level, although there is considerably less evidence compared with the wider population. While economic and environmental aspects have enjoyed fairly wide coverage in relation to the agricultural sector, human wellbeing (including physical and mental health, discussed below) has received less attention. Markussen's work [89] has suggested the importance of relative income (as opposed to absolute income) in determining the happiness of farmers, but there is virtually no evidence of the relationship between happiness and participation in AES schemes. Nevertheless, the evidence also implies that understanding subjective wellbeing, and what shapes it, implies an awareness of the drivers of mental health, as well as an understanding of the unique blend of economic and social pressures that farmers are exposed to. For example, the literature highlights that subjective wellbeing is often shaped very much by the nature and quality of human interaction and forms of social structure. Thus, indicators of stress and social capital will themselves relate to the happiness of farmers.

\subsubsection{High-Level Indicator: Health and Wellbeing-Physical and Mental Health}

Working in the agricultural sector is physically and mentally demanding. In addition to the unique sources of mental stress farmers are subjected to, farm environments are characterised by a broad and changeable range of physical, biological, chemical, and mechanical hazards [90]. This environment causes a series of health issues for farmers, such as respiratory problems, poisoning, ergonomic hazards, and musculoskeletal injuries [90]. While they obviously have individual legitimacy, taken together, physical and mental health can be regarded as core elements of personal wellbeing, itself defined as a positive physical, social, and mental state, which stems from a host of collective goods and relations with people and places [91,92]. It requires basic needs to be met and enhanced by conditions that include supportive personal relationships, community empowerment, financial security, rewarding employment, good health, and a healthy and attractive environment [91]. However, as mentioned, the relative lack of attention on personal development and health (especially mental health) issues of farmers and the wider dynamics of isolation and negative societal perceptions of farming highlights the need for a considerably better understanding. 
In relation to AESs, this dearth of evidence is even more acute, although work on Natural Resource Management (NRM) programs in Australia serve to highlight its significant value. Schirmer et al.'s Australian study [93] suggests that NRM programs influence several important determinants of farmer wellbeing, in particular social capital, self-efficacy, social identity, material wellbeing, and physical and mental health itself. The pathways by which NRM influences these determinants are mediated by distal factors such as changes in land conditions, farmer skills and knowledge, and resources accessible to farmers. These, in turn, are moderated by the design and delivery of NRM programs, suggesting the potential to enhance the health benefits of NRM through specific attention to program design.

\subsubsection{High-Level Indicator: Health and Wellbeing—Stress Levels Due to AES}

Several stressors in a Farmers Stressor Inventory produced by Truchot and Andela [94] were considered relevant and suitable as sub-indicators that are likely to be exacerbated by AES participation. The sub-indicators are:

Stress levels due to AES workload: For some farmers, AES involvement can lead to increases in farm workload with the potential to increase stress levels. It is known that some farmers are already under considerable stress from their existing workloads, working long hours, with little time to relax and recuperate [77]. Therefore, any increased workload from an AES may add to existing stress levels. Alternatively, if an AES is used to restructure the farming system away from intensive production, the AES may reduce the workload.

Stress levels due to AES administration and bureaucracy: A study of the farming community's mental health identified that farmers were increasingly stressed by mounting levels of paperwork [77]. The paperwork was considered to have grown beyond the point it was manageable, especially if IT skills were absent. Stress was also created by systems that were changed before farmers had time to adjust to them and were introduced with insufficient lead-in times. Several AES evaluations have identified an aversion to the paperwork involved and the AES administrative systems employed [95,96]. Therefore, it can be inferred that the level of paperwork and difficulties with an AES's administrative systems can contribute to farmers' stress levels.

Stress levels due to AES inspections: Fear of compliance inspections and inadvertently breaching the AES rules have also added to farmers' stress levels.

Stress levels due to financial issues: Farmers who have financial concerns may face added pressures from the additional demands of an AES. However, as mentioned earlier, there is also evidence that AES payments can help relieve some of the financial pressure on farm businesses [52,64].

Stress levels due to enjoyment of environmental outcomes: Positive impacts on mental health and wellbeing may result from AES participation due to improvements in the onfarm environment, which might include an increase in particular species, such as birds, flowering plants, or particular features, such as ponds or woodlands. For example, Saxby et al. described three farmers involved in an AES project who were motivated to stay at home to enjoy the wildlife attributed to their AES work, when previously they would have visited wildlife sites elsewhere.

\section{Discussion}

This paper aimed to identify social indicators that can be used to measure the impact of AESs in terms of improved quality of AES engagement and social outcomes. This is an under-researched area within the AES field as most indicators used in current AES monitoring and evaluation relate to environmental and economic outcomes only.

The paucity of research into social indicators can partly be explained by some social scientists' reluctance to engage with the positivist methodological approach on which indicators are normally constructed, a point made by Slee [97] in relation to social indicators for forestry. However, we argue that if these indicators are excluded from AES policy monitoring and evaluation programmes, these social factors will be marginalised and overlooked by policy-makers. This is particularly important as there is increasing evidence 
that some of these social factors can positively affect long-term environmental behaviour change, and AES are often criticised for incentivising transactional short-term behavioural change [8]. Social scientists are also concerned that the reductionist and narrowly positivist approach to indicators fails to capture all elements of value and, in particular, the local context. We acknowledge these concerns, but view the use of indicators as part of a broader mix of methods for the monitoring and evaluation of AESs, including qualitative assessments to understand the local context in which responses are given, especially when deployed in association with a trusted farm adviser.

The survey questions used to capture the indicators data (see the Supplementary Materials for a refined version of the survey used in field testing) adopted a series of scale or ranking questions. For some indicators or questions, the scores can be weighted if they are considered more important than others. To provide a single measure for composite indicators (i.e., those made up of various sub-indicators) it is suggested that all scale data are transformed into an appropriate functional range of $0-1$ and the mean of all sub-indicators taken as the single proportional measure. However, like any reductionist approach, it is also important that the indicator is understood in the context. When giving a score, the respondent land managers usually also provide important qualitative information explaining their responses, which should also be captured.

The indicators outlined in this paper are subject to an ongoing assessment. For example, some of the indicators were used in the evaluation of an AES Test and Trial programme in England [97]. Furthermore, the Catchment Sensitive Farming programme in England is looking to integrate social indicators, based on this work, as part of their next phase of programme evaluation (P Smith pers. comm.). It is recognised that these social indicators will form an important communication tool and will assist policy-makers in improving future AES design. To ensure their legitimacy, credibility, and salience, participatory development of these indicators is required through continued testing and feedback. We recommend that the indicators and the questions are tested in a larger pilot survey, based on a stratified randomised sample that is large enough for statistical validation and can examine correlations between sub and composite indicators to reduce them into a more parsimonious set for future application. Further deployment of the survey will test the reliability and validity of the indicators, ensuring the questions obtain consistently robust results over time, and across space, for example allowing regional comparisons that control for spatial as well as sectoral differences.

We envisage that the resulting set of indicators could be used for various purposes. Importantly, the indicators could be utilized as part of a wider AES monitoring and evaluation programme, including in assessing the likely success of a given scheme, how to improve social and environmental outcomes, and how to increase sustained pro-environmental behaviour. They are currently being considered for use in the monitoring and evaluation of the Catchment Sensitive Farming programme and future Environmental Land Management Schemes' pilots in England to better understand the social outcomes of these programmes and the social indicators that drive success.

A further application could be the development of an index of indicators to provide a relative score for the social sustainability of a given scheme. The majority of metrics that make up the index would be derived from ordinal scales based on self-reported attitudinal, behavioural, and experiential variables (such as Attitudes to farming and self-identity) and measured on 1-5 Likert scales. These will be subsequently converted into ratio data in the functional range $0-1$ to help compile the index and enable a variety of inferential, descriptive, and statistical techniques to be applied to the data (Ordinal-scale data are transformed into an appropriate functional range of $0-1$, whereby scaled variables are transformed in the form $(X-\min [X] /(\max [X]-\min [X])$. This produces a transformation of the ordinal codes 1 through 5 (i.e., Strongly Disagree through Strongly Agree): $1=0$; $2=0.25 ; 3=0.50 ; 4=0.75 ; 5=1.0$. Transformation of ordinal-scale variables into the functional range $0-1$ also helps to avoid any bias towards the median score as it enables the absolute value of zero.) Other indicators would comprise interval data demonstrating 
the difference between farm or farmer characteristics, such working hours or holidays taken, or nominal data, such as tenure status or level of formal education.

The indicators could be further tested to identify their ability to predict the agreement trajectory and as proxies for environmental outcomes, including the long-term and 'hidden' outcomes. This could lead to the development of a suite of indicators that could be used by farm advisers to help them assess the quality of engagement an advisee has with their agreement, identify the trajectory of an agreement, as a way of learning about their advisee, and so better support the advisee to improve the delivery of environmental outcomes. For example, the indicators have recently been used in a survey to help understand the characteristics of the farmers who signed up to a conservation land management pilot and how these characteristics link to their levels of engagement with the pilot. Similarly, the indicators could be used as part of adviser training to help advisers understand the social world of agreement holders, the impact of agreements, and how this influences an agreement's success (including encouraging and enabling sustained pro-environmental behaviour change).

\section{Conclusions}

As the environmental quality of agricultural land continues to decline, there is an ever increasing need to find effective policy mechanisms to encourage environmentally beneficial farming practices. Agri-environment schemes were introduced as such a mechanism throughout Europe, and to ensure their effectiveness, they are subject to monitoring and evaluation programmes. However, in this paper, we argue that these programmes are often insufficient as they fail to focus on the trajectory of the farmers in terms of their quality of engagement with environmental management work. It is increasingly being recognised that without more explicit consideration of the people involved in land management as agents of change, the required environmental improvements will not be achieved.

Current AES monitoring and evaluation programmes are also limited in measuring the social sustainability of AESs at the farm level, particularly in terms of their impact on health and wellbeing and quality of life. This lack of attention to the social aspects of AES monitoring and evaluation has meant an under-development in conceptualising and operationalising social indicators compared with environmental and economic indicators.

The aim of this paper, therefore, was, through a comprehensive and systematic literature review, to develop a set of social indicators that can be used to measure the level of farmers' engagement with their scheme agreement and the social sustainability outcomes from participation. Two conceptual frameworks were developed to guide the literature review of 122 documents and, following a short-listing ranking exercise with two sets of experts, 20 high-level (composite) social indicators and associated sub-level (component) indicators were identified.

This paper is a first step in identifying indicators that can measure the quality of AES engagement based on farmers' willingness and ability to engage with a scheme and their agreement, specifically their level of connectedness with others and the impacts of AES engagement on quality of life and health and wellbeing.

In a further step, we have developed a series of survey questions that can be used to capture the indicator data. These questions have been tested and subsequently revised with a small cohort of AES agreement holders. The next step is to further test the reliability and validity of the indicators in a larger survey. The results will be a robust set of social indicators that can be used to measure and assess the quality of an agreement holder's engagement and the social outcomes and sustainability of AESs, which will provide a good indicator of the long-term AES environmental outcomes. The indicators will help to develop a deeper understanding of why and how environmental change happens on farms. 
Supplementary Materials: The following is available online at https:/ / www.mdpi.com/article/10.3390/ su13147820/s1, Survey form S1: Social Indicators Survey Questions.

Author Contributions: Conceptualization, J.M.; data curation, J.M. and H.C.; funding acquisition, J.M.; investigation, J.M., H.C., P.C., G.C., P.G. and M.L.; methodology, J.M., H.C. and P.C.; project administration, J.M.; resources, J.M.; supervision, J.M.; visualization, J.M. and B.B.; writing-original draft, J.M.; writing-review and editing, J.M., H.C., P.C., P.G., B.B., G.C. and M.L. All authors have read and agreed to the published version of the manuscript.

Funding: This research was funded by Natural England and the Department of Environment, Food and Rural Affairs (Defra), grant number LM0478.

Institutional Review Board Statement: Not applicable.

Informed Consent Statement: All subjects gave their informed consent for inclusion before they participated in the study. The interview protocol was reviewed and approved by the University of Gloucestershire's Research Ethics Committee whose procedures align with the Declaration of Helsinki (REC.19.64.1, 6 June 2019).

Data Availability Statement: The literature review dataset is available upon request.

Acknowledgments: We would like to acknowledge the support of Natural England and the Department of Environment, Food and Rural Affairs (Defra) in funding the research project that contributed to this paper. Particular thanks to Sima Sandhu (Defra), Liz Finch (Defra), Phil Smith (Environment Agency), and Jilly Hall (Natural England) for their contributions. Additionally, a huge thanks to the Natural England advisers and the farmers and land managers, along with the Environmental Land Management Social Science Expert Panel members, who gave their valuable time to provide feedback on the indicators and the survey questions.

Conflicts of Interest: The authors declare no conflict of interest. The funders had no role in the design of the study; in the collection, analyses, or interpretation of data; or in the decision to publish the results. They did review the manuscript before submission.

\section{References}

1. European Commission. Technical Handbook on the Monitoring and Evaluation Framework of the Common Agricultural Policy 2014-2020; European Commission: Brussels, Belgium, 2017.

2. Scown, M.W.; Nicholas, K.A. European agricultural policy requires a stronger performance framework to achieve the Sustainable Development Goals. Glob. Sustain. 2020, 3, 3. [CrossRef]

3. Batáry, P.; Dicks, L.V.; Kleijn, D.; Sutherland, W.J. The role of agri-environment schemes in conservation and environmental management. Conserv. Biol. 2015, 29, 1006-1016. [CrossRef]

4. Marggraf, R. Comparative assessment of agri-environment programmes in federal states of Germany. Agric. Ecosyst. Environ. 2003, 98, 507-516. [CrossRef]

5. Ansell, D.; Freudenberger, D.; Munro, N.; Gibbons, P. The cost-effectiveness of agri-environment schemes for biodiversity conservation: A quantitative review. Agric. Ecosyst. Environ. 2016, 225, 184-191. [CrossRef]

6. Burton, R.J.; Kuczera, C.; Schwarz, G. Exploring Farmers' Cultural Resistance to Voluntary Agri-environmental Schemes. Sociol. Rural. 2008, 48, 16-37. [CrossRef]

7. Burton, R.J.; Paragahawewa, U.H. Creating culturally sustainable agri-environmental schemes. J. Rural. Stud. 2011, 27, 95-104. [CrossRef]

8. Morris, C.; Potter, C. Recruiting the new conservationists: Farmers' adoption of agri-environmental schemes in the U.K. J. Rural. Stud. 1995, 11, 51-63. [CrossRef]

9. Schumann, A. Using Outcome Indicators to Improve Policies: Methods, Design Strategies and Implementation; OECD Regional Development Working Papers; OECD: Paris, France, 2016.

10. Department for Environment Food and Rural Affairs. Measuring Environmental Change: Outcome Indicator Framework for the 25 Year Environment Plan; HM Government London: London, UK, 2019.

11. Eaton, M.A.; Noble, D.G. UK Biodiversity Indicators 2020: Technical Background Document: The Wild Bird Indicator for the UK and England; Joint Nature Conservation Committee. 2020. Available online: https://data.jncc.gov.uk/data/7162735c-9fa7-4962aee7-709d242173f1/UKBI2020-TechBG-C5-A.pdf (accessed on 6 July 2021).

12. Department for Environment Food and Rural Affairs. A Green Future: Our 25 Year Plan to Improve the Environment; HM Government London: London, UK, 2018.

13. Mills, J.; Gaskell, P.; Ingram, J.; Dwyer, J.; Reed, M.; Short, C. Engaging farmers in environmental management through a better understanding of behaviour. Agric. Hum. Values 2016, 34, 283-299. [CrossRef] 
14. Ingram, J.; Short, C.J.; Gaskell, P.; Mills, J.; Lewis, N.; Clark, M.; Dennis, E.; Fisher, R.; Owen, I. Entry and Exit from AgriEnvironmental Schemes in Wales; Countryside and Community Research Institute: Cheltenham, UK, 2009.

15. Dwyer, J.; Mills, J.; Ingram, J.; Taylor, J.; Burton, R.; Blackstock, K.; Slee, B.; Brown, K.; Schwarz, G.; Matthews, K. Understanding and Influencing Positive Behaviour Change in Farmers and Land Managers; CCRI, Macaulay Institute: Cheltenham, UK, 2007.

16. Dessart, F.J.; Barreiro-Hurlé, J.; Van Bavel, R. Behavioural factors affecting the adoption of sustainable farming practices: A policy-oriented review. Eur. Rev. Agric. Econ. 2019, 46, 417-471. [CrossRef]

17. Herzon, I.; Mikk, M. Farmers' perceptions of biodiversity and their willingness to enhance it through agri-environment schemes: A comparative study from Estonia and Finland. J. Nat. Conserv. 2007, 15, 10-25. [CrossRef]

18. Wilson, A.G.; Hart, K. Financial Imperative or Conservation Concern? EU Farmers' Motivations for Participation in Voluntary Agri-Environmental Schemes. Environ. Plan. A Econ. Space 2000, 32, 2161-2185. [CrossRef]

19. Siebert, R.; Toogood, M.; Knierim, A. Factors Affecting European Farmers' Participation in Biodiversity Policies. Sociol. Rural. 2006, 46, 318-340. [CrossRef]

20. Sutherland, L.-A.; Mills, J.; Ingram, J.; Burton, R.J.; Dwyer, J.; Blackstock, K. Considering the source: Commercialisation and trust in agri-environmental information and advisory services in England. J. Environ. Manag. 2013, 118, 96-105. [CrossRef] [PubMed]

21. Piasecki, J.; Waligora, M.; Dranseika, V. Google Search as an Additional Source in Systematic Reviews. Sci. Eng. Ethics 2017, 24, 809-810. [CrossRef] [PubMed]

22. Bartkowski, B.; Bartke, S. Leverage Points for Governing Agricultural Soils: A Review of Empirical Studies of European Farmers' Decision-Making. Sustainability 2018, 10, 3179. [CrossRef]

23. Burton, R.J. The influence of farmer demographic characteristics on environmental behaviour: A review. J. Environ. Manag. 2014, 135, 19-26. [CrossRef] [PubMed]

24. Riley, M. How does longer term participation in agri-environment schemes [re]shape farmers' environmental dispositions and identities? Land Use Policy 2016, 52, 62-75. [CrossRef]

25. Department for International Development. Assessing the Strength of Evidence; DFID: London, UK, 2014.

26. Mills, J.; Gaskell, P.; Reed, M.; Short, C.; Ingram, J.; Boatman, N.; Jones, N.; Conyers, S.; Carey, P.; Winter, M.; et al. Farmer attitudes and evaluation of outcomes to on-farm environmental management. Asp. Appl. Biol. 2013, 118, $209-216$.

27. Ahnström, J.; Höckert, J.; Bergeå, H.L.; Francis, C.A.; Skelton, P.; Hallgren, L. Farmers and nature conservation: What is known about attitudes, context factors and actions affecting conservation? Renew. Agric. Food Syst. 2008, 24, 38-47. [CrossRef]

28. Swagemakers, P.; Wiskerke, H.; Van Der Ploeg, J.D. Linking birds, fields and farmers. J. Environ. Manag. 2009, 90, S185-S192. [CrossRef]

29. Fish, R.; Seymour, S.; Watkins, C. Conserving English Landscapes: Land Managers and Agri-Environmental Policy. Environ. Plan. A Econ. Space 2003, 35, 19-41. [CrossRef]

30. Gaskell, P.; Edwards, B.; Courtney, P. Evaluating the Effectiveness of Environmental Stewardship for the Conservation of Historic Buildings, Final Report to Natural England; University of Gloucestershire: Cheltenham, UK, 2014.

31. Jacobson, S.K.; Sieving, K.E.; Jones, G.A.; Van Doorn, A. Assessment of Farmer Attitudes and Behavioral Intentions toward Bird Conservation on Organic and Conventional Florida Farms. Conserv. Biol. 2003, 17, 595-606. [CrossRef]

32. Smallshire, D.; Robertson, P.; Thompson, P. Policy into practice: The development and delivery of agri-environment schemes and supporting advice in England. Ibis 2004, 146, 250-258. [CrossRef]

33. Barnes, A.; Toma, L.; Willock, J.; Hall, C. Comparing a 'budge' to a 'nudge': Farmer responses to voluntary and compulsory compliance in a water quality management regime. J. Rural. Stud. 2013, 32, 448-459. [CrossRef]

34. Morris, J.; Mills, J.; Crawford, I. Promoting farmer uptake of agri-environment schemes: The Countryside Stewardship Arable Options Scheme. Land Use Policy 2000, 17, 241-254. [CrossRef]

35. Charng, H.-W.; Piliavin, J.A.; Callero, P.L. Role Identity and Reasoned Action in the Prediction of Repeated Behavior. Soc. Psychol. Q. 1988, 51, 303. [CrossRef]

36. Burgess, J.; Clark, J.; Harrison, C.M. Knowledges in action: An actor network analysis of a wetland agri-environment scheme. Ecol. Econ. 2000, 35, 119-132. [CrossRef]

37. Burton, R.J. Seeing through the 'good farmer's' eyes: Towards developing an understanding of the social symbolic value of 'productivist' behaviour. Sociol. Rural. 2004, 44, 195-215. [CrossRef]

38. Schmitzberger, I.; Wrbka, T.; Steurer, B.; Aschenbrenner, G.; Peterseil, J.; Zechmeister, H. How farming styles influence biodiversity maintenance in Austrian agricultural landscapes. Agric. Ecosyst. Environ. 2005, 108, 274-290. [CrossRef]

39. Page, G.; Bellotti, W. Farmers value on-farm ecosystem services as important, but what are the impediments to participation in PES schemes? Sci. Total. Environ. 2015, 515-516, 12-19. [CrossRef]

40. Gabel, V.M.; Home, R.; Stolze, M.; Birrer, S.; Steinemann, B.; Köpke, U. The influence of on-farm advice on beliefs and motivations for Swiss lowland farmers to implement ecological compensation areas on their farms. J. Agric. Educ. Ext. 2018, 24, 233-248. [CrossRef]

41. Malkanthi, S.P.; Routray, J.K. Visitor satisfaction in agritourism and its implications for agritourism farmers in Sri Lanka. Int. J. Agric. Manag. 2012, 2, 17. [CrossRef]

42. Wheeler, B.R.; Wilson, P.J. Establishment of a Monitoring Sample of Sites Being Managed under HLS to Maintain or Restore Lowland Fen. Report to Natural England LM0442; Belinda Wheeler: Tavistock, UK, 2016. 
43. Morris, C. Negotiating the boundary between state-led and farmer approaches to knowing nature: An analysis of UK agrienvironment schemes. Geoforum 2006, 37, 113-127. [CrossRef]

44. DeFrancesco, E.; Gatto, P.; Runge, F.; Trestini, S. Factors Affecting Farmers? Participation in Agri-environmental Measures: A Northern Italian Perspective. J. Agric. Econ. 2007, 59, 114-131. [CrossRef]

45. Smithers, J.; Furman, M. Environmental farm planning in Ontario: Exploring participation and the endurance of change. Land Use Policy 2003, 20, 343-356. [CrossRef]

46. Jongeneel, R.A.; Polman, N.B.; Slangen, L.H. Why are Dutch farmers going multifunctional? Land Use Policy 2008, 25, 81-94. [CrossRef]

47. Franks, J.; Emery, S.; Whittingham, M.; McKenzie, A. Farmer attitudes to cross-holding agri-environment schemes and their implications for Countryside Stewardship. Int. J. Agric. Manag. 2016, 5, 78-95.

48. Beedell, J.; Rehman, T. Using social-psychology models to understand farmers' conservation behaviour. J. Rural. Stud. 2000, 16, 117-127. [CrossRef]

49. Potter, C.; Lobley, M. The conservation status and potential of elderly farmers: Results from a survey in England and Wales. J. Rural. Stud. 1992, 8, 133-143. [CrossRef]

50. Potter, C.; Lobley, M. The Farm Family Life Cycle, Succession Paths and Environmental Change in Britain's Countryside. J. Agric. Econ. 1996, 47, 172-190. [CrossRef]

51. Wynn, G.; Crabtree, B.; Potts, J. Modelling Farmer Entry into the Environmentally Sensitive Area Schemes in Scotland. J. Agric. Econ. 2008, 52, 65-82. [CrossRef]

52. Ingram, J.; Gaskell, P.; Mills, J.; Short, C. Incorporating agri-environment schemes into farm development pathways: A temporal analysis of farmer motivations. Land Use Policy 2013, 31, 267-279. [CrossRef]

53. Barreiro-Hurle, J.; Espinosa-Goded, M.; Dupraz, P. Does intensity of change matter? Factors affecting adoption of agrienvironmental schemes in Spain. J. Environ. Plan. Manag. 2010, 53, 891-905. [CrossRef]

54. Wilson, G.A. Factors Influencing Farmer Participation in the Environmentally Sensitive Areas Scheme. J. Environ. Manag. 1997, 50, 67-93. [CrossRef]

55. Dupraz, P.; Vanslembrouck, I.; Bonnieux, F.; Van Huylenbroeck, G. Farmers' participation in European agri-environmental policies. Zaragoza 2002, 28, 31.

56. Walford, N. Agricultural adjustment: Adoption of and adaptation to policy reform measures by large-scale commercial farmers. Land Use Policy 2002, 19, 243-257. [CrossRef]

57. Wynne-Jones, S. Understanding farmer co-operation: Exploring practices of social relatedness and emergent affects. J. Rural. Stud. 2017, 53, 259-268. [CrossRef]

58. Swales, V. Realising Agricultural Landscape-Scale Conservation; RSPB: Sandy, UK, 2009.

59. Mills, J.; Gibbon, D.; Ingram, J.; Reed, M.; Short, C.; Dwyer, J.; Reed, M. Organising Collective Action for Effective Environmental Management and Social Learning in Wales. J. Agric. Educ. Ext. 2011, 17, 69-83. [CrossRef]

60. Emery, S.B.; Franks, J.R. The potential for collaborative agri-environment schemes in England: Can a well-designed collaborative approach address farmers' concerns with current schemes? J. Rural. Stud. 2012, 28, 218-231. [CrossRef]

61. Granovetter, M.S. The Strength of Weak Ties. Am. J. Sociol. 1973, 78, 1360-1380. [CrossRef]

62. Oreszczyn, S.; Lane, A.; Carr, S. The role of networks of practice and webs of influencers on farmers' engagement with and learning about agricultural innovations. J. Rural. Stud. 2010, 26, 404-417. [CrossRef]

63. Polman, N.; Slangen, L. Institutional design of agri-environmental contracts in the European Union: The role of trust and social capital. Wagening. J. Life Sci. 2008, 55, 413-430. [CrossRef]

64. Mills, J. Exploring the social benefits of agri-environment schemes in England. J. Rural. Stud. 2012, 28, 612-621. [CrossRef]

65. De Krom, M. Farmer participation in agri-environmental schemes: Regionalisation and the role of bridging social capital. Land Use Policy 2017, 60, 352-361. [CrossRef]

66. Hall, J.; Pretty, J. Then and now: Norfolk farmers' changing relationships and linkages with government agencies during transformations in land management. J. Farm Manag. 2008, 13, 393-418.

67. Westerink, J.; Opdam, P.; van Rooij, S.; Steingröver, E. Landscape services as boundary concept in landscape governance: Building social capital in collaboration and adapting the landscape. Land Use Policy 2017, 60, 408-418. [CrossRef]

68. Kuhfuss, L.; Préget, R.; Thoyer, S.; Hanley, N.; Le Coent, P.; Désolé, M. Nudges, Social Norms and Permanence in Agri-Environmental Schemes; University of St. Andrews: St. Andrews, UK, 2015.

69. Cusworth, G. Falling short of being the 'good farmer': Losses of social and cultural capital incurred through environmental mismanagement, and the long-term impacts agri-environment scheme participation. J. Rural. Stud. 2020, 75, 164-173. [CrossRef]

70. Saxby, H.; Gkartzios, M.; Scott, K. 'Farming on the Edge': Wellbeing and Participation in Agri-Environmental Schemes. Sociol. Rural. 2017, 58, 392-411. [CrossRef]

71. Herrera, B.; Gerster-Bentaya, M.; Knierim, A. Social indicators of farm-level sustainability. FLINT Deliverable D 2016, 5. Available online: https: / / www.flint-fp7.eu/downloads/reports/D5.2e.pdf (accessed on 6 July 2021).

72. Hayati, D. Literature Review: A Literature Review on Frameworks and Methods for Measuring and Monitoring Sustainable Agriculture; Technical Report; Food and Agriculture Organization of the United Nations: Rome, Italy, 2017.

73. Lebacq, T.; Baret, P.; Stilmant, D. Sustainability indicators for livestock farming. A review. Agron. Sustain. Dev. 2013, 33, 311-327. [CrossRef] 
74. Gregoire, A. The mental health of farmers. Occup. Med. 2002, 52, 471-476. [CrossRef]

75. Parent-Thirion, A.; Fernandez-Macias, E.; Hurley, J.; Vermeylen, G. Fourth European Working Conditions Survey; Office for Official Publication of the European Communities: Luxembourg, Belgium, 2007.

76. Kearney, G.D.; Rafferty, A.P.; Hendricks, L.R.; Allen, D.L.; Tutor-Marcom, R. A Cross-Sectional Study of Stressors Among Farmers in Eastern North Carolina. N. C. Med. J. 2014, 75, 384-392. [CrossRef]

77. Parry, J.; Lindsey, R.; Taylor, R. Farmers, Farm Workers and Work-Related Stress; Health and Safety Executive: Liverpool, UK, 2005.

78. Hounsome, B.; Edwards, R.T.; Edwards-Jones, G. A note on the effect of farmer mental health on adoption: The case of agri-environment schemes. Agric. Syst. 2006, 91, 229-241. [CrossRef]

79. Gorman, M.; Mannion, J.; Kinsella, J.; Bogue, P. Connecting environmental management and farm household livelihoods: The Rural Environment Protection Scheme in Ireland. J. Environ. Policy Plan. 2001, 3, 137-147. [CrossRef]

80. Hřebíček, J.; Valtinyová, S.; Křen, J.; Hodinka, M.; Trenz, O.; Marada, P. Sustainability Indicators: Development and Application for the Agriculture Sector. In Sustainability Appraisal: Quantitative Methods and Mathematical Techniques for Environmental Performance Evaluation; Springer: Berlin/Heidelberg, Germany, 2013; pp. 63-102.

81. Dillon, E.J.; Hennessy, T.; Buckley, C.; Donnellan, T.; Hanrahan, K.; Moran, B.; Ryan, M. Measuring progress in agricultural sustainability to support policy-making. Int. J. Agric. Sustain. 2015, 14, 31-44. [CrossRef]

82. Hansen, B.G.; Stræte, E.P. Dairy farmers' job satisfaction and the influence of automatic milking systems. Wagening. J. Life Sci. 2020, 92, 1-13. [CrossRef]

83. Wezel, A.; Vincent, A.; Nitsch, H.; Schmid, O.; Dubbert, M.; Tasser, E.; Fleury, P.; Stöckli, S.; Stolze, M.; Bogner, D. Farmers' perceptions, preferences, and propositions for result-oriented measures in mountain farming. Land Use Policy 2018, 70, 117-127. [CrossRef]

84. Heo, W.; Lee, J.M.; Park, N. Financial-related psychological factors affect life satisfaction of farmers. J. Rural. Stud. 2020, 80, 185-194. [CrossRef]

85. Helliwell, J.F.; Layard, R.; Sachs, J.; De Neve, J.-E. (Eds.) World Happiness Report; Sustainable Development Solutions Network: New York, NY, USA, 2020.

86. Blanchflower, D.G.; Oswald, A.J. Well-being over time in Britain and the USA. J. Public Econ. 2004, 88, 1359-1386. [CrossRef]

87. Tennant, R.; Hiller, L.; Fishwick, R.; Platt, S.; Joseph, S.; Weich, S.; Parkinson, J.; Secker, J.; Stewart-Brown, S. The WarwickEdinburgh Mental Well-being Scale (WEMWBS): Development and UK validation. Health Qual. Life Outcomes $2007,5,63$. [CrossRef] [PubMed]

88. Easterlin, R.A. Explaining happiness. Proc. Natl. Acad. Sci. USA 2003, 100, 11176-11183. [CrossRef]

89. Markussen, T.; Fibæk, M.; Tarp, F.; Tuan, N.D.A. The Happy Farmer: Self-Employment and Subjective Well-Being in Rural Vietnam. J. Happiness Stud. 2017, 19, 1613-1636. [CrossRef]

90. Nastis, S.A.; Michailidis, A.; Mattas, K. Hazardous agrochemicals, smoking, and farmers' differences in wage-risk tradeoffs. Oper. Res. 2013, 13, 139-152. [CrossRef]

91. Abu Bakar, A.; Osman, M.M.; Bachok, S.; Ibrahim, M.; Mohamed, M.Z. Modelling Economic Wellbeing and Social Wellbeing for Sustainability: A Theoretical Concept. Procedia Environ. Sci. 2015, 28, 286-296. [CrossRef]

92. Dodge, R.; Daly, A.P.; Huyton, J.; Sanders, L.D. The challenge of defining wellbeing. Int. J. Wellbeing 2012, 2, 222-235. [CrossRef]

93. Schirmer, J.; Berry, H.L.; O'Brien, L.V. Healthier land, healthier farmers: Considering the potential of natural resource management as a place-focused farmer health intervention. Health Place 2013, 24, 97-109. [CrossRef] [PubMed]

94. Short, C.; Lewis, N.; Reed, M. Initial Evaluation of the Implementation of Countryside Stewardship in England in 2015/16: Applicant and Non-Applicant Survey. Final Objective 1 Report (Phase 1E2); Countryside and Community Research Institute: Cheltenham, $\mathrm{UK}, 2018$.

95. Staley, J.T.; Lobley, M.; McCracken, M.E.; Chiswell, H.; Redhead, J.W.; Smart, S.M.; Pescott, O.L.; Jitlal, M.; Amy, S.R.; Dean, H.J.; et al. The Environmental Effectiveness of the Higher Level Stewardship Scheme; Resurveying the Baseline Agreement Monitoring Sample to Quantify Change between 2009 and 2016; Full Technical Final Report. Natural England project ECM 6937; Defra: London, UK, 2018.

96. Slee, B. Social indicators of multifunctional rural land use: The case of forestry in the UK. Agric. Ecosyst. Environ. 2007, 120, 31-40. [CrossRef]

97. Nye, C.; Wheeler, R.; Lobley, M. Clinton Devon Estates ELMS Test and Trial Project: Identifying Stakeholder Aspirations, Concerns and Socio-Economic Indicators of Success. Phase One Evaluation; Centre for Rural Policy Research, University of Exeter: Exeter, UK, 2020. 